\section{(6) OPEN ACCESS}

\title{
Topical glyceryl trinitrate treatment of chronic patellar tendinopathy: a randomised, double-blind, placebo-controlled clinical trial
}

\author{
Mirjam Steunebrink, ${ }^{1}$ Johannes Zwerver, ${ }^{2}$ Ruben Brandsema, ${ }^{2}$ Petra Groenenboom, ${ }^{3}$ \\ Inge van den Akker-Scheek, ${ }^{2}$ Adam Weir ${ }^{3}$
}

${ }^{1}$ Department of Steunebrink Sportsmedicine, Eelde, The Netherlands

2Department of

Sportsmedicine, University Medical Center Groningen, Groningen, The Netherlands ${ }^{3}$ Department of Sportsmedicine, Medical Center Haaglanden, Leidschendam, The Netherlands

\section{Correspondence to} Mirjam Steunebrink, Steunebrink Sportsmedicine, Vosbergerlaan 1, $9761 \mathrm{AK}$, Eelde, The Netherlands; mirjamsteunebrink@gmail.com

Received 30 April 2012 Revised 20 July 2012 Accepted 2 August 2012 Published Online First 28 August 2012
To cite: Steunebrink $M$, Zwerver J, Brandsema R, et al. Br J Sports Med 2013, 47, 34-39

\section{ABSTRACT}

Objectives To assess if continuous topical glyceryl trinitrate (GTN) treatment improves outcome in patients with chronic patellar tendinopathy when compared with eccentric training alone.

Methods Randomised double-blind, placebo-controlled clinical trial comparing a 12-week programme of using a GTN or placebo patch in combination with eccentric squats on a decline board. Measurements were performed at baseline, 6, 12 and 24 weeks. Primary outcome measure was the Victorian Institute of Sports Assessment-Patella (VISA-P) questionnaire. Secondary outcome measures were patient satisfaction and pain scores during sports. Generalised estimated equation was used to analyse the treatment, time and treatmentxtime effect. Analyses were performed following the intention-to-treat principle.

Results VISA-P scores for both groups improved over the study period to $75.0 \pm 16.2$ and $80.7 \pm 22.1$ at 24 weeks. Results showed a significant effect for time $(p<0.01)$ but no effect for treatment $\times$ time $(p=0.80)$. Mean Visual Analogue Scores pain scores during sports for both groups increased over the study period to $6.6 \pm 3$ and 7.8 2 3.1. Results showed a significant effect for time $(p<0.01)$ but no effect for treatment $x$ time $(p=0.38)$. Patient satisfaction showed no difference between GTN and placebo groups $(p=0.25)$ after 24 weeks, but did show a significant difference over time $(p=0.01)$. Three patients in the GTN group reported some rash.

Conclusion It seems that continuous topical GTN treatment in addition to an eccentric exercise programme does not improve clinical outcome compared to placebo patches and an eccentric exercise programme in patients with chronic patellar tendinopathy.

\section{INTRODUCTION}

Patellar tendinopathy (PT) (jumper's knee) is a clinical condition characterised by activity-related patellar tendon pain, most commonly at the insertion at the inferior pole of the patella. ${ }^{1}$ It causes significant morbidity in both elite and recreational athletes, particularly those participating in sports involving repeated jumping and landing. ${ }^{2}$ The prevalence of PT among non-elite athletes varies between 2.5\% (soccer players) and 14.4\% (volleyball players). ${ }^{3}{ }^{4}$ In elite sports characterised by high demands on the knee extensors, such as volleyball, basketball and athletics, as many of $40-50 \%$ of patients are affected. ${ }^{3}$ Patellar tendinopathy can severely limit or even end an athletic career. ${ }^{5}$
The underlying pathology of chronic tendinopathies can be characterised as a 'failed healing response'. ${ }^{67}$ Therefore, the management of the more chronic stages of tendinopathy aims to stimulate tendon regeneration and modulation of tendon pain.

Conservative treatment among others include rest, exercise training modification, taping, cryotherapy, NSAID's, electro, laser and shockwave therapies. $^{7-10}$ Different surgical procedures have also been described. ${ }^{11} 12$

Since the 1980s, eccentric training has become the standard treatment in tendinopathy. ${ }^{13}$ Visnes and $\mathrm{Bahr}^{14}$ concluded in their review on eccentric training in PT, that it can be effective, but only when exercises are performed on a 'decline board', provoke some pain and when sport activities are stopped temporarily. Unfortunately, treatment results are often disappointing with only $50-70 \%$ success rates. ${ }^{1114}$

From previous research on tendinopathy of the Achilles tendon, wrist extensors and the supraspinatus, it is known that glyceryl trinitrate (GTN) has a healing effect. ${ }^{15-17}$

Gambito $^{18}$ concluded in his review that there is fairly strong evidence for the effectiveness of GTN in pain reduction in activities of daily living. To our knowledge, no studies have been published on the application of GTN in patients with PT. The aim of this study was therefore to assess if continuous topical GTN treatment improved outcome in patients with chronic PT compared to placebo patches both combined with heavy load eccentric training.

\section{METHODS}

\section{Study design}

A randomised, double-blind, placebo-controlled trial was performed at the sports medicine centres of a general hospital $(\mathrm{MCH})$ and university hospital (UMCG) in the Netherlands. In this study, one group used a placebo patch and another group used a GTN patch. Both groups also followed an eccentric training programme. The double-centre study was announced to general practitioners, sports medicine physicians, physiotherapists and the general public with advertisements on the hospital website and a folder. All patients who visited the outpatient department and who matched the criteria and were willing to participate in the study were included. The treatment with a combination of GTN patches and eccentric training was disseminated as a potentially successful treatment for tendinopathies. 
The study protocol was approved by the Medical Ethical Committee (number 2008-008243-20) at Zuidwest Holland and at the University Medical Center Groningen. All patients gave written informed consent.

\section{Participants}

Inclusion criteria were the presence of chronic PT and age of 18-40 years. The diagnosis was based on clinical findings by an experienced sports physician: all patients had a painful tendon related to activity and/or thickened tendon on palpation. Symptoms had to be present for $>3$ months. MRI and ultrasound were not used. If patients were diagnosed with bilateral PT, only the most painful knee was included. The other knee was treated with the eccentric training programme, but not by using patches. Exclusion criteria were (1) duration $>24$ months, a Victorian Institute of Sports Assessment-Patella (VISA-P) score of 80 or more, previous surgery or a local (corticosteroid) injection of the knee; (2) previous performance of a complete heavy-load eccentric exercise programme of the knee in the last 2 years or inability to perform it because of serious illness; or (3) current pregnancy or other contra-indication for GTN-use. The researcher (MS) or the researcher-assistant (RB) evaluated suitability for inclusion, gave the patients detailed information about the study and obtained informed consent.

\section{Interventions}

The transdermal patches were intact when distributed and were separately packed. The researcher (MS) prepared packages of the patches in one envelope for every patient for treatment lasting 12 weeks. Two kinds of patches were used, active and placebo patches. The active patches (Minitran 5 glyceryltrinitrate patch $3 \mathrm{M}$ Pharma Nederland BV) delivered $5 \mathrm{mg}$ of GTN every $24 \mathrm{~h}$. The placebo patches used were blister-plasters (Kruidvat Renswoude BV).

Patients were instructed on the use of the patches at the time of their initial visit. They were informed that the dosing regimen called for one-quarter of a transdermal patch to be applied daily to the affected patellar tendon. Each quarter patch was to be left in situ for $24 \mathrm{~h}$ and then replaced with a new quarter patch. The patches were to be applied at the site of maximal tenderness within a region of $1-2 \mathrm{~cm}$ around this point. The patients were instructed to rotate the application for the duration of the study in an attempt to avoid irritation of the skin.

At the initial clinical assessment, all patients were also instructed in the performance of an eccentric training programme on a $15^{\circ}-30^{\circ}$ decline board at home. ${ }^{19}$ Each training session was to be completed twice daily, with 3 sets of 15 repetitions being performed at each session. The exercises were done without warming up. The downward (eccentric) component was performed with the affected leg, and the upward (concentric) component was performed with both legs. If both knees were affected, the patient was instructed to use the arms to assist during the concentric phase. The patient was instructed to take $2 \mathrm{~s}$ for each eccentric component of each exercise. The squat was performed with the back in a vertical position and with the knees flexed to a maximum of $60^{\circ}$. The patient was instructed to exercise despite pain during exercise and to stop only if the pain becomes disabling. The patient was advised to attain a pain value of 4 or 5 on a visual analogue scale $(0-$ no pain to 10 -worst pain possible) during the eccentric training sessions. When pain decreased to Visual Analogue Scores (VAS) $<3$, the patient added load in a backpack in $5 \mathrm{~kg}$ increments. If pain increased to $>5$, the patients were instructed to perform the exercise with less weight. This protocol adapts Alfredson's
Achilles tendon exercise programme to the patellar tendon. ${ }^{20}$ All patients were advised to avoid weight-bearing sporting activities for the first 4 weeks. After 4 weeks, a gradual return to sports activities was encouraged. The intensity of sports activities could be increased when there was only mild pain $(\mathrm{VAS}<3$ ) and no increase in morning stiffness. ${ }^{21} 22$

Patients were instructed to avoid the use of co-interventions within the follow-up period. Patients were also given a supply of 20 acetaminophen tablets $(500 \mathrm{mg})$ and were instructed to use them for any headache that they might experience.

\section{Outcome}

All patients completed a self-administered questionnaire, consisting of standardised outcome measures at baseline and after 6, 12 and 24 weeks. The primary outcome measure was the Dutch translation of the VISA-P questionnaire, which quantifies the pain and activity level. ${ }^{23}$ The VISA-P score ranged from 0 to 100 (0-no activity/maximum pain to 100 - maximum activity/ no pain). This is a validated questionnaire, specifically designed for evaluating outcome in PT. Secondary outcome measures were subjective patient satisfaction and pain scores during sports, as rated verbally by the patient on a scale of $0-10$ ( 0 - worst pain to 10 - no pain at all). Pain scale used in this research was different from the VAS mostly used in research, in which 0 is representing no pain at all and 10 representing the worst pain that the patient had ever experienced to prevent confusion by using also the $0-100$ scale in the VISA-P questionnaire. ${ }^{24}$ Patient satisfaction was subjectively rated as poor, fair, good or excellent. A good or excellent result was considered to be successful. Data on side effects, headaches, acetaminophen use, sport activities, compliance with patch application and the eccentric training programme were also recorded at these scheduled visits, using a diary which the patient has to fill in during the first 3 months. According to the study protocol, the primary analysis was performed after 24 weeks of follow-up. After 24 weeks, blinding was disclosed for the primary researcher. Results of a follow-up questionnaire 1 year after the closing of the study were used as a secondary outcome to describe the long-term results.

\section{Sample size}

On the basis of previous studies, the alternative hypothesis was that in the group treated with GTN patches, the VISA-P score would be 13 points higher compared with the group treated with placebo patches. ${ }^{112526}$

The SD of the VISA-P score was estimated at 11 points. We calculated that a sample of 13 in each group was required for the study to detect this difference, with a power of $80 \%$ and an $\alpha$ of 5\%, with two-sided testing at a significance level of 0.05 and assuming 10\% loss to follow-up.

\section{Randomisation}

Randomisation was performed using sealed opaque, identical envelopes. One unblinded sports physician (AW) coded the envelopes with A or B. To ensure concealment of allocation, data on allocation were stored in a secret location. The researcher and the patient were both blinded in this way.

The envelopes were evenly distributed in two boxes at a central place. The randomisation was coordinated by an independent physician. The patient was randomised into groups 1 (placebo group) or 2 (GTN group) by choosing a closed envelope. A block randomisation was performed (block size of four participants). 


\section{Statistical methods}

The statistical analyses were performed with PASW Statistics 18, V.18.0.3 (SPSS Inc, Chicago,Illinois, USA). Differences were considered statistically significant at $\mathrm{p}<0.05$. After determining normal distribution of the data, generalised estimated equation was used to analyse the treatment, time and treatment $\times$ time effect. Covariates having a substantial influence on the outcome variable $(p<0.1)$ were included in the analysis. For the notnormally distributed patient satisfaction rate the Mann-Whitney $\mathrm{U}$ and Wilcoxon signed-rank tests were used. Analyses were performed following the intention-to-treat principle (last observation carried forward).

\section{RESULTS}

The flow of the patients through the trial is shown in figure 1. Between January 2009 and December 2010, 40 patients with patellar tendinopathy visited the sports medical clinics of $\mathrm{MCH}$ and UMCG either directly or through referral. All the patients were examined by experienced sports medicine physicians and those who met the inclusion criteria and were randomised to either GTN or placebo treatment. All were recreational or competitive athletes, playing a variety of sports. Their demographic and clinical baseline characteristics are shown in table 1 .

Corrections for the VAS during sports at time of inclusion were made in further analyses (GTN 4.1 \pm 2.9 and placebo $5.8 \pm 3, \mathrm{p}<0.1)$.

Thirty-three $(82.5 \%)$ patients completed the therapy. None of the athletes stopped using the patches before the 12-week
Table 1 Baseline characteristics for glyceryl trinitrate (GTN) $(n=16)$ and placebo control $(n=17)$ groups

\begin{tabular}{llll}
\hline & $\begin{array}{l}\text { GTN } \\
(\mathbf{n}=16)\end{array}$ & $\begin{array}{l}\text { Placebo } \\
(\mathbf{n}=17)\end{array}$ & $\begin{array}{l}\text { Total group } \\
(\mathbf{n}=33)\end{array}$ \\
\hline $\begin{array}{llll}\text { Personal characteristics } \\
\text { Age (years) }\end{array}$ & $31.9 \pm 9.6$ & $33.8 \pm 10.5$ & $32.9 \pm 10.0$ \\
$\quad$ Sex (men/women) & $11 / 5$ & $14 / 3$ & $25 / 8$ \\
Height (m) & $180.2 \pm 8.6$ & $181.7 \pm 9.7$ & $180.9 \pm 9.1$ \\
Mass (kg) & $78.1 \pm 11.6$ & $84.8 \pm 14.8$ & $81.6 \pm 13.6$ \\
$\quad$ Training hours (h/week) & $4.7 \pm 5.2$ & $3.7 \pm 3.6$ & $4.1 \pm 4.4$ \\
Clinical characteristics & & & \\
$\quad$ VISA-P at baseline & $63.0 \pm 16.4$ & $67.8 \pm 10.9$ & $65.5 \pm 13.8$ \\
$\quad$ VAS during sports at baseline & $4.1 \pm 2.9$ & $5.8 \pm 3.0$ & $5.0 \pm 3.1^{*}$ \\
Duration of symptoms (weeks) & $47 \pm 39$ & $49 \pm 36$ & $48 \pm 37$ \\
Unilateral/bilateral symptoms & $9 / 7$ & $14 / 3$ & $23 / 10$ \\
\hline
\end{tabular}

*Significant difference between GTN and placebo groups: $p=<0.05$.

Presented numbers are means \pm SD or numbers.

VAS, Visual Analogue Scores; VISA-P, Victorian Institute of Sports Assessment-Patella.

period of eccentric training has ended. The compliance with the eccentric training programme was more than $70 \%$. The seven patients who dropped out of the study directly after the inclusion had similar baseline characteristics compared to the subjects who completed the treatment.
Figure 1 Flowchart of participants through the study and reasons of withdrawal.

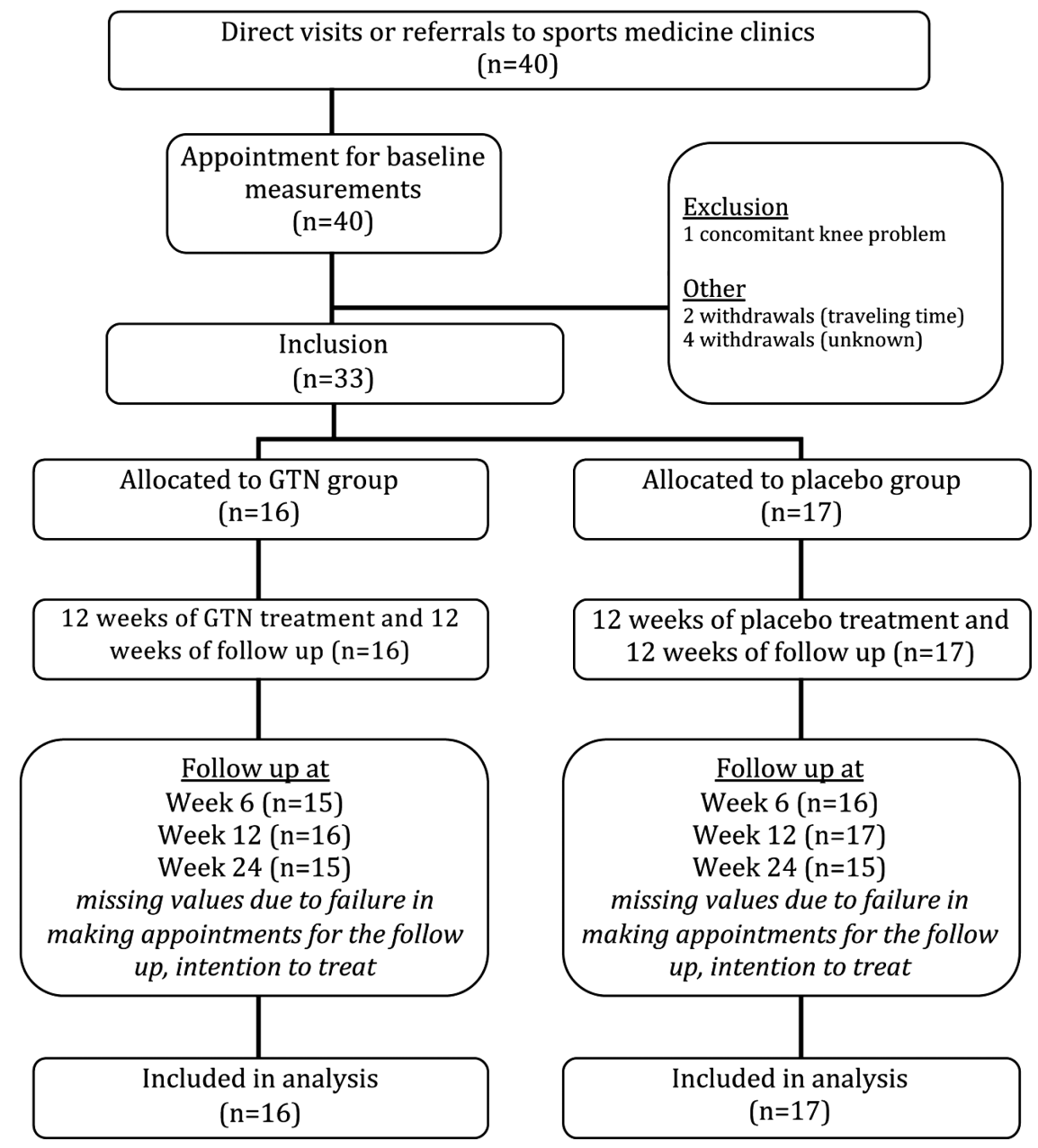


Table 2 Main outcome measures (VISA-P and VAS during sports) at 6, 12 and 24 weeks in the glyceryl trinitrate (GTN) and placebo groups

\begin{tabular}{|c|c|c|c|c|c|c|c|c|c|c|c|}
\hline & \multicolumn{4}{|c|}{ GTN $(n=16)$} & \multicolumn{4}{|c|}{ Placebo $(n=17)$} & \multirow[b]{2}{*}{$\begin{array}{l}\text { Difference } \\
(95 \% \mathrm{Cl}) \\
6 \text { weeks }\end{array}$} & \multirow[b]{2}{*}{$\begin{array}{l}\text { Difference } \\
(95 \% \mathrm{Cl}) \\
12 \text { weeks }\end{array}$} & \multirow[b]{2}{*}{$\begin{array}{l}\text { Difference } \\
(95 \% \mathrm{Cl}) \\
24 \text { weeks }\end{array}$} \\
\hline & $\begin{array}{l}\text { Baseline } \\
\text { (mean } \\
\text { (SD)) }\end{array}$ & $\begin{array}{l}6 \text { weeks } \\
\text { (mean } \\
\text { (SD)) }\end{array}$ & $\begin{array}{l}12 \text { weeks } \\
\text { (mean (SD)) }\end{array}$ & $\begin{array}{l}24 \text { weeks } \\
\text { (mean (SD)) }\end{array}$ & $\begin{array}{l}\text { Baseline } \\
\text { (mean } \\
\text { (SD)) }\end{array}$ & $\begin{array}{l}6 \text { weeks } \\
\text { (mean } \\
\text { (SD)) }\end{array}$ & $\begin{array}{l}12 \text { weeks } \\
\text { (mean (SD)) }\end{array}$ & $\begin{array}{l}24 \text { weeks } \\
\text { (mean (SD)) }\end{array}$ & & & \\
\hline $\begin{array}{l}\text { VISA } \\
\text { score } \\
(0-100)\end{array}$ & $63(16.4)$ & $64(21.8)$ & $73(15.3)$ & 75 (16.2) & $67.8(10.9)$ & $67.7(15.6)$ & 73.7 (20.7) & $80.7(22.1)$ & $\begin{array}{l}1.1 \\
(-10.5 \text { to } 12.7)\end{array}$ & $\begin{array}{l}4.2 \\
(-7.9 \text { to } 16.2)\end{array}$ & $\begin{array}{l}-1.2 \\
(-12.5 \text { to } 10)\end{array}$ \\
\hline $\begin{array}{l}\text { VAS } \\
\text { score } \\
(0-10) \\
*\end{array}$ & $4.1(2.9)$ & $5.9(3.1)$ & $6.6(2)$ & $6.6(3)$ & $5.8(3)$ & $5.4(3.3)$ & $6.6(3.7)$ & $7.8(3.1)$ & $\begin{array}{l}2.3 \\
(-0.7 \text { to } 5.3)\end{array}$ & $\begin{array}{l}1.8 \\
(-0.8 \text { to } 4.2)\end{array}$ & $\begin{array}{l}0.4 \\
\text { (-2 to } 2.8)\end{array}$ \\
\hline
\end{tabular}

${ }^{*} 0=$ worst pain ever, $10=$ no pain

VAS, Visual Analogue Scores; VISA-P, Victorian Institute of Sports Assessment-Patella.

\section{Primary outcome measure}

The baseline mean VISA-P scores and changes after 6, 12 and 24 weeks are shown in table 2 . The scores for the GTN and placebo groups were $63.0 \pm 16.4$ and $67.8 \pm 10.9$ at baseline, respectively. Both groups improved over the study period to $75 \pm 16.2$ and $80.7 \pm 22.1$ (figure 2). Results showed a significant effect for time $(p<0.01)$ but did not show an interaction effect for treatment $\times$ time $(p=0.80)$.

\section{Secondary outcome measures}

Mean VAS during sports at baseline, 6, 12 and 24 weeks are shown in table 2 . The scores for GTN and placebo groups were $4.1 \pm 2.9$ and $5.8 \pm 3$ at baseline, respectively. Both groups increased over the study period to $6.6 \pm 3$ and $7.8 \pm 3.1$ (figure 3 ). Results showed a significant effect for time $(\mathrm{p}<0.01)$ but did not show an interaction effect for treatment $\times$ time $(p=0.38)$.

The patient satisfaction rate (table 3 ) showed no significant difference between GTN and placebo groups $(p=0.25)$ after 24 weeks, but did show a significant difference over time $(\mathrm{p}=0.01)$.

Three of the patients in the GTN group reported some rashes (redness of the skin) caused by the patches. However, they all continued to use the patches.

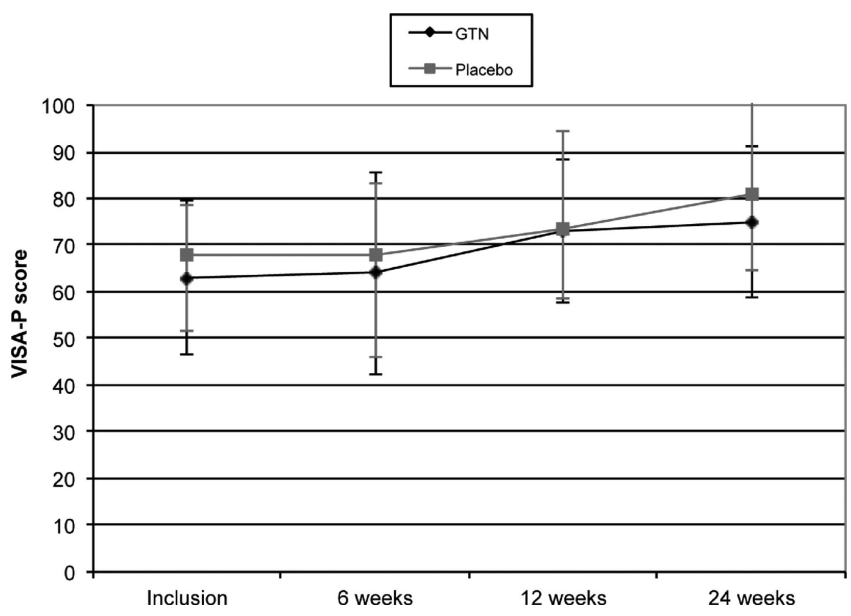

Figure 2 Victorian Institute of Sports Assessment-Patella scores for treatment (glyceryl trinitrate) and placebo groups at the time of inclusion and after 6, 12 and 24 weeks.

\section{DISCUSSION}

The main finding of this randomised placebo-controlled study is that there seems to be no benefit of using topical GTN in addition to an eccentric exercise programme in the management of patients with chronic PT. Although the primary validated and disease-specific clinical outcome measure, the VISA-P score improved significantly in both groups over the 24-week study period, there was no statistically significant difference between GTN and placebo groups. The VAS and patient satisfaction also improved in both groups as well as without a significant difference between the groups. GTN can be considered as a safe treatment; only three patients reported minor side effects.

This is the first randomised controlled trial (RCT) to evaluate the effectiveness of GTN in chronic PT. Recently other studies investigating the use of GTN in tendinopathies also found no effect. McCallum et al did a follow-up study of 58 patients with chronic lateral epicondylosis at the elbow, treated with 6 months of topical GTN or placebo in combination with a tendon rehabilitation programme. GTN did not offer any additional clinical benefit 5 years after discontinuation of therapy. ${ }^{27}$ A review by Cumpston et al, in which three small studies were included of patients with rotator cuff disease who received topical GTN, alone or in combination, compared to placebo or

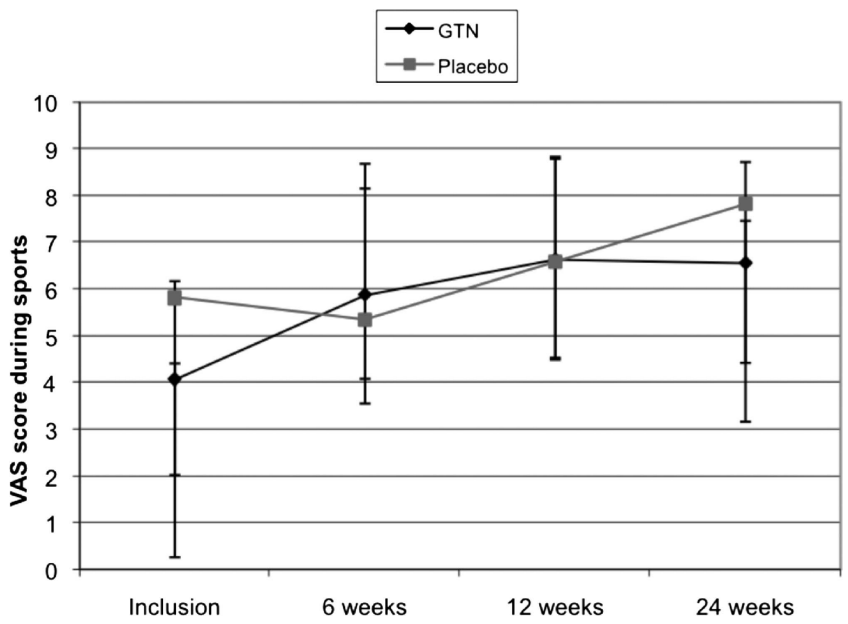

Figure 3 Visual Analogue Scores during sports for treatment (glyceryl trinitrate) and placebo groups at the time of inclusion and after 6, 12 and 24 weeks. 
Table 3 Patient satisfaction rates

\begin{tabular}{|c|c|c|c|c|c|c|c|c|}
\hline & \multicolumn{4}{|c|}{ GTN $(n=16)$} & \multicolumn{4}{|c|}{ Placebo $(n=17)$} \\
\hline & Baseline & 6 weeks & 12 weeks & 24 weeks & Baseline & 6 weeks & 12 weeks & 24 weeks \\
\hline Poor & 9 & 4 & 4 & 3 & 5 & 4 & 4 & 3 \\
\hline Fair & 5 & 8 & 3 & 5 & 9 & 5 & 4 & 3 \\
\hline Good & 1 & 3 & 9 & 6 & 0 & 7 & 6 & 3 \\
\hline Excellent & 0 & 0 & 0 & 1 & 0 & 0 & 3 & 6 \\
\hline
\end{tabular}

GTN, glyceryl trinitrate.

active therapy, showed that there is insufficient evidence to be certain about their longer-term effects. ${ }^{28}$ Kane et $a l^{29}$ also found no additional clinical benefit of GTN over standard nonoperative treatment for non-insertional Achilles tendinopathy in their randomised controlled clinical trial.

On the contrary, Paoloni et al have previously demonstrated efficacy of continuous topical GTN treatment in a dose of $1.25 \mathrm{mg} / 24 \mathrm{~h}$ using patches, when combined with daily exercise rehabilitation, in treating chronic tendinopathies including lateral epicondylosis, ${ }^{15}$ non-insertional Achilles tendinopathy ${ }^{16}$ and supraspinatus tendinopathy. ${ }^{17}$ Moreover, a recent systematic review and meta-analysis by Gambito found strong evidence that GTN reduced pain in activities of daily living for chronic tendinopathies as compared with placebo. ${ }^{18}$

One reason for this conflicting evidence could be that in studies of Paoloni et al, research has been done in chronic tendinopathies of the main tendon body. In this study of PT, it could be that mostly the enthesis instead of the main tendon body shows tendinopathy. This could be a major difference, as many clinicians consider that in tendinopathies of the Achilles tendon, for example, the subgroup of patients with insertional Achilles tendinopathy are more difficult to manage. ${ }^{30}$ This could be the same in PT.

Another explanation can be a difference in outcome measure. In his review, Gambito used pain in activities of daily living as the primary outcome measure, while in this study of PT the primary measure is the VISA-P, which quantifies the pain and activity level and not only activities in daily living. Also the secondary outcome measures in this study (subjective patient satisfaction and pain scores) were sports related. In general, different outcomes measures will often explain a difference in results in the same kind of RCTs. In some studies disease-specific validated outcomes scores have been used, like the VISA score, while in other only more general non-validated outcomes like the VAS have been used. Other possible explanations for difference in outcomes could be the difference in sample size and in power analysis with inadequacy of relevant RCTs. Hence, results of this study must also be interpreted with some caution, because of the low power of 80 as a result of a relatively high percentage lost to follow-up and because of the small differences at baseline between groups in VAS during sports.

Some clinical issues must be considered. The diagnosis of the PT was based on the typical history and location of tenderness after examination by an experienced sports physician. No MRI and no ultrasound imaging were performed. This could be considered a limitation of the study. It is well known, however, that there is limited correlation between clinical symptoms and ultrasound or MRI, ${ }^{31} 32$ and that they are not the gold standard. Another limitation of this study is that the tendon rehabilitation programme used in this clinical trial was home based and not supervised. By using verbal checks at each follow-up we were able to reach a reasonable compliance over $70 \%$.
In this clinical trial, the delivery of nitric oxide (NO) via transdermal GTN patches was chosen because of their ease of dosing and application. NO has exhibited a role in fibroblast proliferation, collagen synthesis ${ }^{33}$ and contraction of collagen lattices. $^{34}$ Also macrophage angiogenic activity (important for wound healing) is dependent on NO synthase, ${ }^{34}$ and NO synthase activity is upregulated in tendinopathy. ${ }^{35}$ However, one can doubt whether sufficient absorption of NO through the skin and into the degenerative area of the tendon occurs. Recently Lenz and Gillespie ${ }^{35}$ demonstrated a significant increase in the plasma concentration of GTN when individuals exercise compared with rest, so one might expect some absorption while performing eccentric exercises. Yet, the question remains as to whether NO concentrations reached a high enough level to be effective in stimulating tendon regeneration. Also, as gradual return to sport activities was encouraged, sweat on the knee might have had an effect on the absorption of NO, but to our knowledge no studies have been published on this subject. Common side effects of continuous topical GTN treatment include headache and contact dermatitis. In earlier studies by Paoloni using topical GTN on lateral epicondylosis, supraspinatus tendinopathy and Achilles tendinopathy, where also $1.25 \mathrm{mg} / 24 \mathrm{~h}$ patches were used, rather high numbers of side effects were reported. About $5-8 \%$ of patients had to stop treatment due to headache and $5 \%$ of patients due to rash. In this study none of the patients reported headache and only three patients reported some slight rash but continued to use the patches. Although quite speculative, the much lower number of side effects might indicate that absorption in the knee area was not sufficient and the concentration of NO has been to low to produce both healing and side effects. Further studies should determine whether higher dosages of GTN are more effective as an additional treatment in the management of PT.

\section{CONCLUSION}

It seems that continuous topical GTN treatment in addition to an eccentric exercise programme does not improve clinical outcome in patients with chronic PT compared to placebo patches in combination with an eccentric exercise programme.

\section{What is this study adds}

In the treatment of patients with chronic patellar tendinopathy, it seems that the application of topical glyceryl trinitrate in addition to an eccentric training programme does not improve clinical outcome compared to placebo patches and an eccentric training programme. 
Acknowledgements This research was supported in part by Medical Center Haaglanden, Leidschendam. We also like to thank Hans Tol and Bas Bulder for their invaluable contributions.

Contributors Mirjam Steunebrink has planned, conducted and reported the research during her scholarship as a Medical Doctor in Sportsmedicine. Therefore, AW guided her through this process, he is responsible for the overall content. PG conducted part of the research in Medical Center Haaglanden, whereas JZ and RB conducted this research in the University Medical Center Groningen. Also, JZ was very helpful with reporting all this research information into this article. IvdA-S and RB did all the statistical analysis.

Competing interests None.

Ethics approval Medical Ethical Committee Zuidwest Holland and at the University Medical Center Groningen.

Provenance and peer review Not commissioned; externally peer reviewed.

Open Access: This is an Open Access article distributed in accordance with the Creative Commons Attribution Non Commercial (CC BY-NC 3.0) license, which permits others to distribute, remix, adapt, build upon this work non-commercially, and license their derivative works on different terms, provided the original work is properly cited and the use is non-commercial. See: http://creativecommons.org/ licenses/by-nc/3.0/

\section{REFERENCES}

1 Blazina ME, Kerlan RK, Jobe FW, et al. Jumper's knee. Orthop Clin North Am 1973:4:665-78.

2 Kannus P. Etiology and pathophysiology of chronic tendon disorders in sports. Scand J Med Sci Sports 1997;7:78-85.

3 Lian OB, Engebretsen L, Bahr R. Prevalence of jumper's knee among elite athletes from different sports — a cross-sectional study. Am J Sports Med 2005;33:561-7.

4 Zwerver J, Bredeweg SW, van den Akker-Scheek I. Prevalence of jumper's knee among nonelite athletes from different sports: a cross-sectional survey. Am I Sports Med 2011;39:1984-8.

5 Kettunen JA, Kvist M, Alanen $\mathrm{E}$, et al. Long-term prognosis for jumper's knee in male athletes—a prospective follow-up study. Am I Sports Med 2002;30:689-92.

6 Cook JL, Khan KM. What is the most appropriate treatment for patellar tendinopathy? Br J Sports Med 2001;35:291-4.

7 Peers KHE, Lysens RJJ. Patellar tendinopathy in athletes—current diagnostic and therapeutic recommendations. Sports Med 2005;35:71-87.

8 Khan KM, Cook JL, Bonar F, et al. Histopathology of common tendinopathiesupdate and implications for clinical management. Sports Med 1999;27:393-408

9 Rees JD, Maffulli N, Cook J. Management of tendinopathy. Am J Sports Med 2009;37:1855-67.

10 Fredberg U, Bolvig L. Jumper's knee-review of the literature. Scand J Med Sci Sports 1999;9:66-73.

11 Bahr R, Fossan B, Loken S, et al. Surgical treatment compared with eccentric training for patellar tendinopathy (jumper's knee): a randomized, controlled trial. I Bone Joint Surg Ser Am 2006;88:1689-98.

12 Coleman BD, Khan KM, Maffulli N, et al. Studies of surgical outcome after patellar tendinopathy: clinical significance of methodological deficiencies and guidelines for future studies. Scand I Med Sci Sports 2000;10:2-11.

13 Stanish W, Rubinovich R, Curwin S. Eccentric exercise in chronic tendinitis. Clin Orthop 1986:208:65-8.

14 Visnes H, Bahr R. The evolution of eccentric training as treatment for patellar tendinopathy (jumper's knee): a critical review of exercise programmes. $\mathrm{Br}$ I Sports Med 2007:41:217-23.
15 Paoloni JA, Appleyard RC, Nelson J, et al. Topical nitric oxide application in the treatment of chronic extensor tendinosis at the elbow: a randomized, double-blinded, placebo-controlled clinical trial. Am J Sports Med 2003:31:915-20.

16 Paoloni JA, Appleyard RC, Nelson J, et al. Topical glyceryl trinitrate treatment of chronic noninsertional Achilles tendinopathy. A randomized, double-blind, placebo-controlled trial. J Bone Joint Surg Am 2004;86:916-22.

17 Paoloni JA, Appleyard RC, Nelson J, et al. Topical glyceryl trinitrate application in the treatment of chronic supraspinatus tendinopathy: a randomized, double-blinded, placebo-controlled clinical trial. Am J Sports Med 2005;33:806-13.

18 Gambito ED, Gonzalez-Suarez CB, Oquinena TI, et al. Evidence on the effectiveness of topical nitroglycerin in the treatment of tendinopathies: a systematic review and meta-analysis. Arch Phys Med Rehabil 2010:91:1291-305.

19 Zwerver J, Bredeweg SW, Hof AL. Biomechanical analysis of the single-leg decline squat. Br J Sports Med 2007;41:264-8.

20 Alfredson $\mathrm{H}$, Pietila T, Jonsson P, et al. Heavy-load eccentric calf muscle training for the treatment of chronic Achilles tendinosis. Am I Sports Med 1998;26:360-6.

21 Visnes $\mathrm{H}$, Hoksrud A, Cook J, et al. No effect of eccentric training on jumper's knee in volleyball players during the competitive season: a randomized clinical trial. Clin J Sport Med 2005;15:227-34.

22 Silbernagel KG, Thomee R, Eriksson Bl, et al. Continued sports activity, using a pain-monitoring model, during rehabilitation in patients with Achilles tendinopathy: a randomized controlled study. Am J Sports Med 2007:35:897-906.

23 Zwerver J, Kramer T, Akker-Scheek I. Validity and reliability of the Dutch translation of the VISA-P questionnaire for patellar tendinopathy. BMC Musculoskelet Disord 2009; 10:102.

24 Johnson C. Measuring pain. visual analog scale versus numeric pain scale: what is the difference? J Chiropr Med 2005;4:43-4.

25 Cook JL, Khan KM, Kiss ZS, et al. Prospective imaging study of asymptomatic patellar tendinopathy in elite junior basketball players. J Ultras Med 2000;19:473-9.

26 Visentini PJ, Khan KM, Cook JL, et al. The VISA score: an index of severity of symptoms in patients with jumper's knee (patellar tendinosis). Victorian Institute of Sport Tendon Study Group. J Sci Med Sport 1998;1:22-8.

27 McCallum SD, Paoloni JA, Murrell GA. Five-year prospective comparison study of topical glyceryl trinitrate treatment of chronic lateral epicondylosis at the elbow. $\mathrm{Br} J$ Sports Med 2011;45:416-20

28 Cumpston $M$, Johnston RV, Wengier L, et al. Topical glyceryl trinitrate for rotator cuff disease. Cochrane Database Syst Rev 2009;3:CD006355.

29 Kane TP, Ismail M, Calder JD. Topical glyceryl trinitrate and noninsertional Achilles tendinopathy: a clinical and cellular investigation. Am I Sports Med 2008;36:1160-3

30 Kearney R, Costa ML. Insertional achilles tendinopathy management: a systematic review. Foot Ankle Int 2010;31:689-94.

31 Cook JL, Khan KM, Kiss ZS, et al. Asymptomatic hypoechoic regions on patellar tendon ultrasound: a 4-year clinical and ultrasound followup of 46 tendons. Scand J Med Sci Sports 2001;11:321-7.

32 Shalaby M, Almekinders LC. Patellar tendinitis: the significance of magnetic resonance imaging findings. Am J Sports Med 1999;27:345-9.

33 Murrell GA. Oxygen free radicals and tendon healing. I Shoulder Elbow Surg 2007;16:5208-14.

34 Schwacha MG. Gammadelta T-cells: potential regulators of the post-burn inflammatory response. Burns 2009;35:318-26.

35 Murrell GA. Using nitric oxide to treat tendinopathy. Br I Sports Med 2007:41:227-31.

36 Lenz TL, Gillespie N. Transdermal patch drug delivery interactions with exercise. Sports Med 2011:41:177-83. 